\title{
The Creativity of 'Unspecialization:' A Contemplative Direction for Integrative Scholarly Practice
}

\author{
Kathleen Galvin and Les Todres, IHCS Bournemouth University, United Kingdom \\ kgalvin@bournemouth.ac.uk
}

\section{Abstract}

Within the context of health and social care education, attempts to define 'scholarship' have increasingly transcended traditional academic conceptions of the term. While acknowledging that many applied disciplines call for a kind of 'actionable knowledge' that is also not separate from its ethical dimensions, engagement in the caring professions in particular provides an interesting exemplar that raises questions about the nature and practice of 'actionable knowledge:' how is such knowledge from different domains (the head, hand and heart) integrated and sustained? This paper is theoretical and wishes to outline some philosophical ideas that may be important when considering the characteristics of the kind of scholarship for caring practices that draw on deep resources for creativity and integration. Firstly, there is an attempt to clarify the nature of scholarly practice by drawing on Aristotle's notion of 'phronesis' (practical wisdom). Secondly, a more meditative approach to the integration of knowledge, action and ethics is highlighted. Finally, its implications for scholarship are introduced, in which scholarly integration may best be served by more contemplative ways of being and thinking. Drawing on Heidegger and Gendlin, we consider the challenges of contemplative thinking for pursuing scholarly practice. We articulate contemplative thinking as an unspecialized mode of being that is given to human beings as an intimate source of creativity. The sense in which unspecialization can be cultivated and practiced is discussed.

\section{Introduction}

In this paper we wish to contribute to an emerging debate about what scholarship means in a changing world where domains of knowledge have become exceedingly complex, in that knowledge is increasingly specialized and raises significant challenges for how these different discourses relate to one another in both theory and practice. Such complexity is particularly highlighted in caring professions such as nursing, midwifery, medicine, psychology, social work 
and other professions allied to medicine, where immersion in practice has exposed a deep inseparability between knowledge, ethics and action.

Boyer (1990) put forward a model of scholarship that emphasized the integration of a number of scholarly domains including research, teaching and application. In 1999, the American Association of Colleges of Nursing (AACN, 1999) adopted a position statement on scholarship that built on Boyer's work. Riley et al. (2002) took this further and proposed that such scholarship is setting-related but not setting-dependent, that it is holistic and fluid, and that it combines knowledge, experience, rigour and a service base. In a wide-ranging article, they consider some of the complexities of knowledge-in-action and knowledge-for-action, in which the sources of knowing are intimately intertwined with experience and practice. In this way, Riley et al. (2002) refer to how a very local and situated engagement is relevant to knowledge production: "The intimacy of the relationship is essential; because it provides important information and it is the therapeutic vehicle for applying knowledge" (p. 386).

These ideas draw on a tradition of thought that focuses on forms of applied knowledge (e.g. Carper, 1978; Schon, 1983; Benner et al., 1996; van Manen, 1999). By emphasizing action, service orientation and immersion in practice, this tradition integrates knowing and being (epistemology and ontology), and includes the ethical dimension of the 'good.'

In this paper, we meditate further on the integration of knowledge, ethics and action and pursue the following goals:

- Locating the separation of the domains of knowledge, ethics and action within a historical context;

- Considering the nature of 'phronesis' - the kind of knowledge that is already not separate from ethics and action;

- Formulating 'scholarship' as a 'seamless' way of being, rather than the integration of separate domains of knowledge, ethics and action;

- Indicating some directions for promoting a scholarship that draws on more contemplative directions, which open up creative, 'unspecialized' possibilities for feeling, thinking and doing. The term 'unspecialized' is developed in relation to Heidegger's thought and expresses a fundamentally human way of being that cannot be objectified and as such is a deep source of creativity

We conclude by considering whether the creativity of "unspecialization" can be practiced, and draw on Heidegger and Gendlin as helpful guides. 


\section{A Conceptual Exploration of Scholarship for Caring Practices}

\section{Historical context: the 'dignity' and 'disaster' of modernity}

In this section we would like to briefly offer one perspective on the gradual specialization of knowledge. Although there are many accounts of the fragmentation of knowledge domains (e.g., see Weber 1963; Taylor 1985 and Habermas, 1990), we offer a brief historical analysis that draws on Wilber's (1995) discussion of the post-modern separation of science, art and morality. Understanding modernity and postmodernity as historical phenomena, the first of these can be identified with the project of the enlightenment in which the progress of natural science became a primary source of knowledge, value and justice. Postmodernity correspondingly refers to a certain disillusionment with the hopes that of scientific progress would bring both epistemologically and ethically. (We acknowledge that particular strands of postmodern thought have been accused of certain excesses of relativism and even narcissism but also acknowledge other strands within this discourse that emphasize respect for diversity in terms of values and culture as well as the validity of heterogeneous ways of knowing.)

It is within this distinction between modernity and postmodernity as a historical phenomenon that Wilber (1995) brings together a historical analysis of the sociology of knowledge that began with Weber (1963), and was pursued further by Taylor (1985) and Habermas (1990). Central to this analysis are the developments of modernity that heralded the differentiation science, art and morality. This differentiation allowed much progress to take place in the spheres of the sciences, the arts, and justice, because each could pursue its activities without having to be too contaminated by the concerns of the other. Science was less constrained by aesthetic or ethical concerns, which allowed it to concentrate on the pursuit of knowledge in the objective world. This heralded technological progress in attempts to control the environment. Art, too, became much less classically wedded to morality or to an accurate and knowing portrayal of reality. What Wilber calls the "dignity of modernity" refers to the positive value of modernity, the advantages of creating the space for specialization, where welcome progress could be made within each domain's own terms and in accordance with their own logic:

By the end of the eighteenth century, science, morality and art were even institutionally differentiated as realms of activity in which questions of truth (science), of justice (morals), and of taste (art) were autonomously elaborated, that is, each of these spheres of knowing [was pursued] under its own specific aspect of validity. (Habermas, 1990, p. 19)

Such differentiation, however, poses the question that has become increasingly apparent in our times: how can these different domains become re-integrated? According to Wilber, the disaster of modernity is that these domains, through their specialized paths, have become dissociated 
from one another: "...if the dignity of modernity was the differentiation of the Big Three, the disaster of modernity would be that it had not yet found a way to integrate them" (Wilber, 1995, p. 416).

Habermas (1990) has been strident in his criticism of what he called the 'colonisation of the lifeworld' by social engineering, technical approaches to practical life and subjectivity, and the increasing control by 'experts' of political and social life. All this constituted a 'commodification;' to turn the values of life into mere commodities. Habermas (1990) elaborated on how the differentiation of the domains of science, art and morality created a situation of uneven development in these spheres and how a healing of such dissociation is needed. We are currently scrambling to address the ethics and justice of scientific progress, the art of applied knowledge and the boundaries of art and the scientific and aesthetic dimensions of law. A metaphorical way to express Wilber's question about integration would be: how does the head (knowing), the heart (ethics) and the hand (the art of action) function as one body? What is this way of being and what are its implications for the meaning of scholarship?

In postmodern times, we cannot simply turn back to a form of simplistic holism in a way that denies specialization and diversity. However, in honouring differentiation, we can, nevertheless, pursue such differentiated domains through an understanding of the fundamental non-separation of science, morality and the art of action in the way that life moves. We may need to make this background much clearer when considering scholarship and so we refer to Aristotle's notion of a way of being in which knowing, doing and valuing are fundamentally inseparable.

\section{The nature of 'phronesis:' the kind of knowledge that is already not separate from ethics and action}

Polkinghorne (2004) advocates an expanded notion of rationality that can accommodate living situations that are highly specific to their context, that involve the unpredictability of the human realm, and where exceptions to rules often apply: "Effective practices of care require that practitioner actions are decided by their situated and timely judgements" (p. 2). Furthermore:

Practical choices in situations calling for actions to bring about the human good require a kind of thought that can deal with complex and competing goals and take into account the timing and context of the action, as well as the uniqueness and particular characteristics of the situation and person for whom the action is undertaken. (p. 21)

In this view, scholarship is tested by the "...situations in which we run out of rules" (Brown, 1988, p. 139). So what kind of knowing and way of being is adequate for this task? Polkinghorne refers back to ancient Greece, before the differentiation of the value spheres had taken place, to Aristotle.

Aristotle distinguished between the kind of deliberations that were appropriate for making things (techne) and those that were appropriate for acting in the human realm. He used the term 'phronesis' to mean a practical wisdom that can address a plurality of values. 
The most characteristic function of a man of practical wisdom is to deliberate well: no ones deliberates about things that cannot be other than they are, nor about things that cannot be directed to some end, an end that is a good attainable by action. In an unqualified sense, that man is good at deliberating who, by reasoning, can aim at and hit the best thing attainable to man by action. (Aristotle, 1141b 9-14)

The complexity of living situations means that such plurality often results in conflict between values. Conflicts such as the good of an individual versus the good of the collective, or conflicts that surround the inherent risks of acting versus not acting when certainty of outcome cannot be guaranteed. The sources of understanding and knowing that are drawn on in such situations are multiple and are already based on an interwoven fabric of knowing, morality and the art of applied action. Such interwoven 'fabric' is only separated into categories by means of reflection it is originally a seamless way of being and moving. Polkinghorne sees such a way of being as an expansion of the traditional understanding of rationality; it is intelligent in that it varies with situations, is receptive to particulars, and has the quality of improvisation. Polkinghorne links Aristotle's notion of phronesis to a number of current developments in philosophy and psychology that articulate a broader understanding of rationality. We merely wish to indicate these developments in order to acknowledge that there are currently a number of ways to develop a kind of practical wisdom that emphasizes the way human beings are embedded in their world.

This broader understanding of rational thinking includes Epstein's (1994) 'experiential thinking,' Lakoff and Johnson's (1999) 'embodied rationality' and Gendlin's (1992) notion of the 'felt sense.' These notions resonate deeply with Aristotle's phronesis. However, in this paper, we would like to highlight 'empathic imagination' as a kind of practical wisdom of particular relevance to caring practices.

First of all, empathic imagination involves imaginative thinking. Murray (1986) draws on Heidegger to show how this is not simply an imaginary experience, such as imagining being able to fly like Peter Pan. Imaginative thinking is more directed in that it may be used to solve complex problems. It is also a participative form of knowing in that you imaginatively put yourself in a series of scenarios so as to be open to the possibilities of those scenarios. Such thinking is particularly relevant when a unique situation asks you to dwell with the specific complexities of that situation. Imaginatively we see what is there and what is not there and move forward in time to imagine outcomes and possibilities. In that way, we participatively and imaginatively move in many directions, in a 'rhizomatic' manner, just as a rhizome is a plant with an intricacy of interconnections. In imaginative thinking there is the interconnection between past and future, feeling, thought and situation; a multiplicity of felt connections. Emphasizing the difference between generality and particularity, Nussbaum (1990) indicates the complexity of such interconnected, imaginative presence:

Instead of ascending from the particular to the general, deliberative imagination links particulars without dispensing with their particularity. It would involve, for example, the ability to recall past experiences as one with, as relevant to, the case at hand, while still conceiving of both with rich and vivid concreteness. (p. 78) 
As one kind of deliberative imagination, empathic imagination goes further. It brings in an interpersonal focus whereby the world of another person is imagined. The phenomenological tradition has been helpful in articulating an approach to understanding others by trying to suspend our own preconceptions and 'taking a walk in another person's shoes.' Developmental psychologists such as Kohlberg (1981) have shown how moral development requires the ability to shift from an egocentric position to one that can see something from another's point of view. Empathic imagination is thus already an interwoven fabric of thought, ethics and action in that an individual is fundamentally engaged in being with and, in some cases, being for another as a source of knowledge and action. The meaning of caring is founded on this possibility, with its imagination of what another's world may be like. It provides rich, detailed and context-specific possibilities for knowing and acting. It is consequently a form of phronesis (practical wisdom) that may be centrally important when considering the meaning of scholarship for caring practices.

\section{Scholarship as a seamless way of being rather than the integration of separate domains of knowledge, ethics and action}

Our consideration of the kind of scholarship that is central to caring practices has so far emphasized a kind of integration of knowledge ethics and action that intimately work together as a coherent movement. For caring practices we have emphasized how this kind of integration is centrally informed by an empathic sensibility that underpins such integration. We would like, however, to consider further the nature of this kind of integration.

There is a danger in any analysis of 'integration' that integration of knowing, ethics and action is achieved by actively doing such integration. This often serves to increase the feeling that we are 'in over our heads' (Kegan, 1994), scrambling to increase our professional life-loads by becoming everything: researchers, teachers, business-fellows and internet junkies perusing the latest evidence. The feeling quality of this is often impending fragmentation rather than coherence. But the question is: what gets 'dropped out' in all this increased doing?

An alternative view of integration that is more contemplative and less strident is provided by Heidegger (1960), and is essentially contained in his image of a clearing in the forest. Once such a clearing has been attained within this image, integration does not have to be actively strived for because what was thought of as requiring integration (as separate domains) is found to already be there, 'together.' This view of integration suggests an uncovering of what can obscure it rather than an active search to put things together, as if this needs to be achieved through ardor and artifice. Such uncovering requires a more contemplative direction and draws on a critique by Heidegger of the spirit of technology, and how this can obscure integrative possibilities as a way of being.

In the 1920s, Heidegger (1926/1962) was already facing fundamental questions about the relationship between the spirit of technology and more foundational issues of being human. He wasn't against technological progress but wanted to strike a note of caution about how the essence of technology is such that it is defining not only the world around us, but also ourselves as objects. Furthermore, he was concerned that as we became increasingly capable of 
objectifying ourselves in this way, something very important would become obscured - namely our unspecialized capacity of being. Such unspecialized capacity is the place where knowing, ethics and action were never separate. It is rather 'one song' (Todres, 2000) or a movement that is always unfinished because it is open to the new and is already an interconnection of head, hand and heart; it is the realm of possibility. In this view, integration has always been happening and we only become excessively concerned with integration if it is blocked or if we wish to overly control its direction.

Nurturing the space for such being-possibilities does not mean that nothing is happening. Applying this to a kind of scholarship that is a seamless movement of head, hand and heart would mean that the ongoing learning and opportunities within our professional and personal lives could 'settle.' The importance of 'settling' as a kind of clearing that allows integration to be, does not eradicate the value of pursuing specialized developments or the activity of relating these developments to one another. Rather, it offers some relief that striving in a specialized way is not the only path to productivity - that our unspecialized capacities for being can be productive. As touched on earlier in this paper, this is the place from where integration is already vitally tasted. The question then changes from how to 'effortfully' achieve a scholarly integration of knowledge, ethics and action, to how to bring specialized activities into the spaciousness of being where integration is already 'humming.' Approaching the question in this way may raise particular challenges for how we support this possibility. The kind of scholarship that attempts to accommodate such a how may be best conceptualized as a way of being that needs a different kind of support and permission by our learning and institutional contexts. The challenge is then to recognize such times of settling as a creative resource for seamless knowing-valuing-acting. The feeling-quality of such settling and connecting with this natural integrity may be one of vitality. There may be a certain sense of excitement and coherence as we begin to give space to and trust these possibilities of being. Such a sense of vitality and coherence may also mitigate a feeling of burnout. We consider later how a more contemplative scholarly path can be given permission and supported with reference to Gendlin's philosophy of entry into the implicit. But first we would like to consider the path of contemplation as a way of being that is relevant to scholarship for caring practices.

\section{A contemplative scholarship: can unspecialization be practiced?}

Turner (1994), Van Manen (1999) and others have indicated the complexity of the notion of 'practice' in relation to pedagogy. In this view, practice is not merely instrumental in the sense of applying pre-determined methodologies, but is rather embedded in ways of being that are prereflective and often spontaneous. Does this mean that such practice 'just happens' or is there a way that we can take more conscious responsibility for it? Van Manen, drawing on Turner, indicates how such practice is nevertheless a certain kind of activity that can be cultivated: "...in spite of this intangibility, the concept of practice must include the connotation of something transferable, teachable, transmittable, or reproducible" (Van Manen, 1999).

Van Manen is writing about the practice of teaching. However, for the purposes of this paper, we wish to consider practice in relation to the question of whether the integrative 
development (in terms of head, heart and hand) of the scholar can be actively cultivated, and in what sense an opening to the creativity of unspecialization can be practiced.

This direction has been pursued by several writers under different rubrics and in different contexts. This includes Bachelard's (1964) notion of 'reverie,' Gadamer's (1986/1994) concept of 'play' and various mytho-poetic directions for education (MacDonald, 1981; Willis, 2005). In particular, Heidegger (1959/1966), in his writings on contemplative thinking, gives us some helpful directions about the sense in which such an opening to being can be 'practiced.' His argument is associated with a long-standing tradition of what Keats has called 'negative capability.' Negative capability means the natural 'generativity' that arises, not by positively seeking integration in a goal-directed way, but by allowing integration 'to be.' This occurs during periods of 'letting go,' 'lying fallow' or having space and time for what has been called 'blue skies thinking' (see, for example, Claxton, 1997, for a fuller discussion of this logic).

In an essay entitled 'The Age of the World Picture,' Heidegger (1977) cautioned against the tendency to secure the precedence of methodology over presence as a way of opening to understanding. He was concerned that the way science was being organized and practiced resulted in the 'scholar' disappearing and the 'research worker' becoming a technologist whose specialising concerns prematurely close down the creativity of unspecialization in a selfreferenced and self-reifying way:

The human becomes that being upon which all that is, is grounded as regards the manner of its Being and its truth. The human becomes the relational centre of that which is as such. (Heidegger, 1977, p. 128; translation adapted based on the original German)

Such a self-referencing, specialized perspective forms the foundation of what Heidegger called calculative thinking. It is characterised by a thinking that is preoccupied with existing patterns in the way we organise, categorise and particularize phenomena.

Heidegger distinguished contemplative thinking from calculative thinking. Our argument proposes that it is contemplative thinking that is centrally relevant to the question of whether the creativity of unspecialization can be practiced. Contemplative thinking is about how one can think in a receptive way that is open to the excess of being beyond oneself (being-in-the-world) and not the more calculative type of thinking that is 'always on the move' and merely 'doing' an existing pattern of organized thought.

This does not mean that such presence and openness to 'being-in-the-world' is passive. There is a certain 'waiting' in it; but that waiting is a form of actively practicing a 'negative capability' that keeps at bay the kind of possessive 'willing' that prematurely grasps at what is already known. In this way, contemplative thinking can be said to be actively practised in the sense that it holds open the possibility of not knowing, and so allows a release into the openness and creativity of a more unspecialized realm: "We must develop the art of waiting, releasing our hold..." (Hixon, 1989, p. 4). And this is not far away. It is very near; nearer than our habitual ways of thinking. In releasing ourselves from our more habitual thinking, a less specialized presence is possible, one that is open to profiles of the world that are at the edge of the known, 
where novelty occurs. "Openness is not due to any specific point of view but is rather the absence of single-perspective perceiving and thinking" (Hixon, 1989, p. 9).

In relation to an integrative vision of scholarship, we thus wish to include the creativity of unspecialization. Heidegger has provided us with clues for a more contemplative direction in this pursuit; one that is receptive, but that can nevertheless be practised by actively becoming aware of an alternative to calculative thinking. But we would like to take this one step further and propose some directions for such practice based on Eugene Gendlin's philosophy of 'entry into the implicit' (Gendlin 1991). Gendlin's notion of 'the implicit' refers to the place where unspecialized possibilities have their life. Entry into the implicit then involves an experiential movement that allows the aliveness of the implicit to be sensed and to function as an ongoing creative source of possible new meanings. As such, Gendlin provides one possible practice that can serve scholarly integration through the remembrance to discipline our specialized concerns and thus give way to the 'letting be' of our more unspecialized possibilities.

In his philosophy of entry into the implicit, Gendlin sets out a relational ontology in which contemplative thinking can be practiced by attending to ones own lived body and, as such, opens up the excesses of being-in-the-world beyond pre-existing patterns.

\section{Gendlin's philosophy as a practice of opening the creativity of unspecialization}

Gendlin's philosophy of entry into the implicit (Gendlin, 1991) builds on the thoughts of Heidegger and Merleau-Ponty. It focuses on how the lived body can open profiles of the world beyond pre-patterned thought. The phrase 'entry into the implicit' means that words, thoughts and representations are formulated and come from an experiential practice based on attending to the lived body's sense of felt meaning in any moment. Two practices arise out of this philosophy. One is called 'focusing', the other, 'thinking at the edge.'

\section{Focusing}

Focusing describes an experiential practice of attending to the relationship between language and the aliveness or excess of what language is trying to point to, by grounding such aliveness in the lived body's felt sense. Through a felt sense, meaning is apprehended in a holistic way that is more than its formulation in language and already-patterned thought. The felt sense is full of the excess of the life-world - its fleshly textures and abundances of meanings. The felt-sense is "...implicitly intricate in a way that is more than what is already formed or distinguished" (Gendlin, 1992). The practice of focusing is then a body-based hermeneutics that goes back and forth between this 'more than' of the lifeworld, and the many ways of patterning the lifeworld, as it comes to form in language and thought. 


\section{Thinking at the edge}

Thinking at the edge is a stepped process that uses focusing but builds theory from the freshness of the focusing process. In such a way, it aims "...to think and speak about our world and our selves by generating terms from a felt sense. Such terms formulate experiential intricacy rather than turning everything we think about into externally viewed objects" (Gendlin, 2004).

\section{Opening up unspecialized possibilities}

Both these practices may provide direction for how to open unspecialized possibilities through an embodied contemplative approach. In order to illustrate this in a concrete way, let us refer to an illustration that Gendlin provides (the use of (...) in the following passage refers to the 'more than words can say' of the felt sense (the many ellipses are in the original):

An artist stands before an unfinished picture, pondering it, seeing, feeling, bodily sensing it, having a ... Suppose the artist's ... is one of some dissatisfaction. Is that an emotional reaction, simply a feeling-tone? No indeed. Implicit in the ... is the artist's training, experience with many designs, and much else. But more: the ... is also the implying of the next line, which has not yet come. The artist ponders 'what it needs.' It needs some line, some erasure, something moved over, something ... . The artist tries this and that, and something else, and erases it again each time. The ... is quite demanding. It recognizes the failure of each attempt. It seems to know precisely what it wants and it knows that those attempts are not it. Rather than accepting those, a good artist prefers to leave a design unfinished, sometimes for years. (Gendlin, 1992)

This illustration shows how the lived body is an important gate to the alive and implicit 'more' where unspecialized possibilities can be touched. So, in answer to our earlier question of whether unspecialization can be practiced, we suggest that it can and that Gendlin offers important understandings and practices that, although active in a certain sense, can honour the kind of contemplative attitude that is hospitable to being addressed by new meanings from 'the more' as we pursue scholarly enquiry.

In relation to contemplative scholarly practice relevant to care, we can imagine the following vignette. Sarah a nurse has been struggling on the ward with a deep sense of discomfort she experienced in a case conference. This discomfort is highly complex but implicitly 'there' in the 'more' of her felt sense. 'In it' is the 'head,' 'hand' and 'heart' as already together. But as she settles and lets go of her specialized concern to be a competent staff nurse and even her specialized concern to be professional, scholarly and caring, she attends to what wants to come from her felt sense of the whole of everything together there. Her discomfort carries a number of different dimensions: how she had recently read a scholarly work on Levinas that her think about the nature of respect, how certain experiences in her past professional and personal life had impressed upon her the importance of being careful not to assume what another 
needs, and how all this and some other things gave her a sense of possible directions of action that were consistent with the uncomfortable feeling of what was missing in terms of the kind of respectful care that she would like to offer in this particular situation. In this situation she thus actively made space for a more contemplative approach to the integration of head, hand and heart that was implicit in the 'pre-formed' unspecialization of her felt sense. Yet this was productive. A clear understanding and possible action did come, that was ultimately supported in a way that included what could be called an integrated scholarly way of being as articulated in this paper.

\section{Conclusion}

We have tried to set out the idea of a more contemplative scholarship, one that draws on a natural movement in 'being' to embody and live in a knowing, valuing and action-oriented way. We looked at historical evidence before the 'doing' of integration became such a dilemma and highlighted virtue inhering in our unspecialized possibilities of being, while at the same time questioning how our specialized engagements can be held more vitally within these unspecialized movements. In particular, in relation to scholarship for caring practices, we noted how empathic imagination is a central faculty for integrating the head, hand and heart.

So why are contemplative practices important for the kind of scholarship that acknowledges an integration of head, hand and heart? In an increasingly specialized and even fragmented world, the humming integration of head, hand and heart that naturally occurs becomes easily obscured by the excessive compartmentalisation of attention to specialized tasks. The essence of creativity requires the kind of space that only comes with a slowing down, an inbreath, that for a moment, releases a relentless hold. The kind of integrative focus offered in this paper may suggest some interesting directions for consideration as to how contemplative orientations for scholarly practice can be supported, guarded and nurtured. 


\section{References}

American Association of Colleges in Nursing, (AACN). (1999). Hallmarks of scholarly nursing practice. Washington DC: Author.

Aristotle. (1983). Nichomachean ethics. Indianapolis: Hackett Publishing Company.

Bachelard, G. (1964). The Poetics of space. Boston: Beacon.

Benner, P., Tanner, C. \& Chesla, C. (1996). Expertise in nursing practice: Caring, clinical judgment and ethics. New York: Springer.

Boyer, E.L. (1990). Scholarship reconsidered: Priorities of the professoriate. Princeton: Carnegie Endowment for the Advancement of Teaching.

Brown, H.I. (1988). Rationality. New York: Routledge.

Carper, B.A. (1978). Fundamental patterns of knowing in nursing. Advances in Nursing Science, $1(6), 13-23$.

Cahoone, L.E. (Ed.) (1996) From modernism to postmodernism. An anthology. Oxford: Blackwell.

Claxton, G. (1997). Hare brain, tortoise mind: Why intelligence increases when you think less. London: Fourth Estate.

Epstein, S. (1994). Integration of the cognitive and the psychodynamic unconscious. American Psychologist, 49(8), 709-724.

Gadamer, H-G. (1986/1994). Truth and method (2 ${ }^{\text {nd }}$ rev. ed.). New York: Seabury Press.

Gendlin, E.T. (1962). Experiencing and the creation of meaning. Glencoe: Free Press.

Gendlin, E.T. (1991). Thinking beyond patterns: body, language and situations. Retrieved October $15^{\text {th }}$, 2006 from www.focusing.org/tbp.html

Gendlin, E.T. (1992). The primacy of the body, not the primacy of perception: how the body knows the situation and philosophy. Man and World 25 (3- 4) 341-353. Retrieved October $15^{\text {th }}$, 2006 from http://www.focusing.org/pdf/primacy_excerpt.pdf

Gendlin, E.T. (2004). Introduction to 'Thinking at the edge.' The Folio. Thinking at the Edge: A new Philosophical Practice, 19 (1), 1-10. Retrieved October 15 ${ }^{\text {th }}$, 2006 from www.focusing.org/tae-intro.html 
Habermas, J. (1990) The philosophical discourse of modernity. Cambridge: MIT Press.

Heidegger, M. (1962). Being and time. Oxford: Blackwell.

Heidegger M. (1960). "The origin of the work of art." In Poetry, language and thought (pp.1787). New York: Harper and Row.

Heidegger, M. (1966). Discourse on thinking. New York: Harper \& Row.

Heidegger, M. (1977). The Age of the world picture. In: The question concerning technology and other essays (pp. 115-154). New York: Harper \& Row,

Hixon, L. (1989) Coming home: The experience of enlightenment in sacred traditions. Los Angeles: Tarcher/Perigee.

Kegan, R. (1994). In over our heads: The mental demands of modern life. London: Harvard University Press.

Kohlberg, L. (1981). Essays on moral development (Vol. 1). San Francisco: Harper.

Lakoff, G. \& Johnson, M. (1999). Philosophy in the flesh: The embodied mind and its challenge to western thought. New York: Basic Books.

MacDonald, J.B. (1981). Theory, practice and the hermeneutic circle. Journal of curriculum Theorizing, 3(2), 130-138.

Murray, E.L. (1986). Imaginative thinking and human existence. Pittsburgh, PA: Duquesne University Press.

Nussbaum, M.C. (1990). Love's knowledge: Essays on philosophy and literature. Oxford: Oxford University Press.

Polkinghorne, D. (2004). Practice and the human sciences: The case for a judgement based practice of care. Albany, NY: SUNY.

Riley, J.M., Beal, J., Levi, O. \& McCausland, M.P. (2002). Revisioning nursing scholarship. Journal of nursing Scholarship, 34(4), 383-389.

Schon, D. (1983). The reflective practitioner. New York: Basic Books.

Taylor, C. (1985). Philosophy and the human sciences - Philosophical papers 2. Cambridge: Cambridge University Press. 
Todres, L. (2000). Embracing ambiguity: transpersonal development and the phenomenological tradition. Religion and Health, 39(3), 227-237.

Turner, S. (1994). The social theory of practices. Chicago: University of Chicago Press.

Van Manen, M. (1999). The practice of practice. Retrieved October $15^{\text {th }}$, 2006 from http://www.phenomenologyonline.com/max/articles/practice.html

Weber, M. (1963). The sociology of religion. Boston: Beacon.

Wilber, K. (1995). Sex, ecology, spirituality: The spirit of evolution. London: Shambhala.

Willis, P. (2005). Mythopoetic communities of practice in postgraduate Educational Research. In: Stehlik, T. \& Carden, P. (Eds). Beyond communities of practice: Theory as experience (pp. 47-66). Brisbane: Post Press. 